\title{
Detection of stress and the effects of central nervous system depressants by gastrointestinal smooth muscle electromyography in wakeful rats
}

\author{
K.F. Szúcss ${ }^{\mathrm{a}}$, G. Grosz ${ }^{\mathrm{b}}$, M. Süle ${ }^{\mathrm{b}}$, A. Sztojkov-Ivanov ${ }^{\mathrm{a}}$, E. Ducza ${ }^{\mathrm{a}}$, A. Márki ${ }^{\mathrm{a}}$, A. Kothencz ${ }^{\mathrm{a}}$, \\ L. Balogh ${ }^{\mathrm{c}}$, R. Gáspár ${ }^{\mathrm{a}, *}$ \\ ${ }^{a}$ Department of Pharmacodynamics and Biopharmacy, Faculty of Pharmacy, University of Szeged, Eötvös utca 6, 6720 Szeged, Hungary \\ ${ }^{\mathrm{b}} \mathrm{MDE}$ GmbH, Altrottstrasse 31, 69190 Walldorf, Germany \\ ${ }^{\mathrm{c}}$ Institute of Physical Education and Sports Science, Juhász Gyula Faculty of Education, University of Szeged, Hattyas sor 10, 6725 Szeged, Hungary
}

\section{A R T I C L E I N F O}

\section{Keywords:}

Brain-gut axis

Corticosterone

Electromyography

Rat

Stress

\begin{abstract}
A B S T R A C T
Aims: The altered gut-brain interaction can be in the background of functional gastrointestinal (GI) disorders. In the GI tract, the slow-wave myoelectric signals can be detected by electromyography (EMG). The aims of our study were to follow up the stress induced alteration in the GI tract by smooth muscle EMG in wakeful rats. Main methods: The GI tract myoelectric activity of male rats was measured by an electrode pair under the abdominal skin, the responses were detected and analyzed by a software using fast Fourier transformation. Animals were immobilized and treated with either diazepam or haloperidol. The plasma corticosterone level was determined by ELISA kit, the levels of drugs were measured by HPLC, while the direct GI effects of the compounds were tested in an organ bath.

Key findings: Significant correlation $\left(\mathrm{r}^{2}=0.52\right)$ was found between the immobilization induced increase in the EMG spectra of the GI tract segments and the increase in corticosterone plasma levels. The stress-reducing effects of diazepam and haloperidol were also detectable by smooth muscle EMG in the GI tract. No direct smooth muscle actions of the drugs were found in organ bath studies.

Significance: The smooth muscle EMG instrument can measure the level of acute stress and is applicable for the investigation of central nervous system affecting drugs through the GI tract in awake rats. This is the first tool to measure the stress response via the GI tract reactions. The technique may open a new perspective in the diagnosis and therapy of psychosomatic disorders.
\end{abstract}

\section{Introduction}

The gut-brain axis creates a two-way communication network created by the complex system of the enteric nervous system (ENS), cerebral nerves and the humoral system. The ENS can affect all intestinal functions, including motility and all gastrointestinal (GI) motor functions, absorption and secretion, the regulation of food intake [1]. Functional GI malfunctions can be the consequences of dysregulation in the gut-brain axis. The altered gut-brain interaction can be in the background of functional GI disorders and other motility diseases, such as gastroesophageal reflux disease and irritable bowel syndrome. The investigation of the gut-brain axis and the enteric plexus activity helps to promote the understanding of GI diseases and the therapies for GI disorders and stress-induced GI malfunctions [2-4].

Patients with anxiety and depressive disorders have a higher incidence of functional GI disorders that are frequently unrecognized [5]. One of the major reasons for this low recognition is the lack of a reliable method to detect the GI tract motility in psychiatric disorders. Such a method would be useful to help the diagnosis of given mental disorders and to assess the efficacy of the therapies both for mental and GI problems [6]. There is a need for the development of an in vivo technique which allows us to determine the strength of muscle contraction and the possible electrical abnormalities in motility disorders related to psychiatric problems [7].

Motion artifacts are major obstacles to the various electromyographic examinations in wakeful subjects. Studies have demonstrated that the results of electroencephalographic (EEG) records can be modified by muscle work during the record because the frequencies of the brain and myogenic activity are overlapping. The electromyographic (EMG) signals can be eliminated by computerized screening from EEG records [8]. The skeletal muscle induced motion artifacts have higher amplitude compared to the basal activity, which may cause large distortion in the measurement. Therefore motion artifacts have to be filtered out, however, in the case of overlapping frequencies, filtering can

\footnotetext{
* Corresponding author at: Department of Pharmacodynamics and Biopharmacy, Faculty of Pharmacy, University of Szeged, H-6701, P.O. Box 121, Hungary.

E-mail address: gaspar@pharm.u-szeged.hu (R. Gáspár).
} 
result in significant data loss $[9,10]$.

In the GI tract, slow-wave signals can be detected by EMG. In anesthetized rat, we successfully identified the characteristic slow-wave signals and frequency values for the stomach, ileum, cecum and uterus, which were $3-5,20-25,1-3$ and $1-2.5$ cycles per minute (cpm), respectively. Although the pregnant uterine and cecal smooth muscle signals are overlapping, the myometrial activity is predominant in late pregnancy, while cecal signals are much more robust in nonpregnant animals. In pregnant animals the different pharmacological relativity of the uterus and the large intestine was also clearly detectable by EMG [11,12].

Based on these results, we hypothesized that our smooth muscle EMG method - accomplished with a digital cutter for removing motion artifacts - can be applicable in wakeful rats under normal and stress conditions. The aims of our study were to follow up the stress condition induced alteration in the GI tract and to measure the effects of central nervous depressants by smooth muscle EMG in wakeful rats.

\section{Materials and methods}

\subsection{Housing and handling of the animals}

The study was conducted using male Sprague-Dawley rats (10-14 weeks old, body weight: $260-350 \mathrm{~g}$ ). The animals were treated in accordance with the European Communities Council Directives (86/ 609/ECC) and the Hungarian Act for the Protection of Animals in Research (Article 32 of Act XXVIII). All experiments involving animal subjects were carried out with the approval of the Hungarian Ethical Committee for Animal Research (registration number: IV/3796/2015).

Sprague-Dawley rats (Charles-River Laboratories, Budapest, Hungary) were housed at $22 \pm 3{ }^{\circ} \mathrm{C}$ and a relative humidity of $30-70 \%$, under a $12 \mathrm{~h}$ light $/ 12 \mathrm{~h}$ dark cycle. Standard rodent pellet food (Charles-River Laboratories, Budapest, Hungary) and tap water were provided ad libitum.

\subsection{Electromyographic measurements, drug treatments and immobilization}

Male rats were anesthetized with isoflurane inhalation, then a bipolar disk electrode pair (SEN-15-2; MDE GmbH, Walldorf, Germany) was fixed subcutaneously $1 \mathrm{~cm}$ right from the midline above the gastrointestinal tract (the distance between the two electrodes was $20 \mathrm{~mm}$ ). The connecting cable of the sensor to the swivel was led subcutaneously and the terminal was led out through the skin of the neck. After the placement of the sensor, the abdominal and cervical incision surfaces were closed by surgical sutures and staples, respectively.

The basal activity was detected the day after the placement of the sensors. Food and water were withdrawn $2 \mathrm{~h}$ before and during the detection. The animals were placed one by one in cages with highpitched walls, with a transparent wall at the front side. The animals were not restricted in their movements for $30 \mathrm{~min}$ while recording basal GI tract activity (control). Then the rats were anesthetized with $3.5 \%$ isoflurane inhalation and placed and fixed onto a glass plate by strong sticky belts. The rats were laid on the abdomen and were not able to move or turn around. After full awakening (3-5 min), the GI activity was recorded again for $30 \mathrm{~min}$ under this stress condition. When diazepam $\left(5 \mathrm{mg} \mathrm{kg}^{-1}\right)$ or haloperidol $\left(1 \mathrm{mg} \mathrm{kg}^{-1}\right)$ was administered intraperitoneally for the given groups of rats, the treatments were done after recording the basal activity. Then 30-min recording was carried out for each drug to determine their actions before and during stress condition.

The myoelectric signals were recorded and analyzed by an on-line computer system by the S.P.E.L. Advanced ISOSYS Data Acquisition System (MDE GmbH, Walldorf, Germany). Electromyographic (EMG) signals were amplified by using a custom-made amplifier. All analogue signals were filtered with a first-order bandpass Bessel-type filter with a frequency of $0-30$ cycles per minute (cpm) and were converted to digital signals at a sample rate of $2 \mathrm{~Hz}$. The recorded signals were analyzed by fast Fourier transformation (FFT). The FFT of 30-min periods were evaluated. The frequency of the electric activity was characterized by cpm, and the magnitude of the activity was described as power spectrum density (PsD). When more than one peak was found in the spectrum, the highest peak was considered as characteristic for the given GI tract segment. During the evaluation, the EMG spectrum of basal activity was compared to the activities after drug treatment or during stress period. The stress-induced alterations were expressed as percentage of the spontaneous activity. The $\mathrm{PsD}_{\max }$ values were compared statistically (one-way ANOVA) by using the computer program Prism 5.0. (GraphPad Software, USA).

To remove the motion artifacts, a digital cutter was built into the software. The edge values of the limiter were set by the motion artifactfree sections of the records. Thereby, we were able to cut the artifact signals by their obviously high outlier amplitude.

\subsection{Collection of plasma and organ samples}

At the end of each period of $30 \mathrm{~min}$, samples of $0.5 \mathrm{ml}$ blood were collected from the tail veins into $1 \mathrm{ml}$ tubes containing $\mathrm{K}_{3}$ EDTA $(0.6 \mathrm{mg} /$ tube $)$ and centrifuged $\left(1700 \times \mathrm{g}, 10 \mathrm{~min}, 4^{\circ} \mathrm{C}\right)$ to separate plasma. The plasma samples were stored at $-20^{\circ} \mathrm{C}$ until hormone assay and HPLC analysis. The organ samples for haloperidol determination were collected after termination by $\mathrm{CO}_{2}$ inhalation. Brain, lung and liver tissue samples were homogenized in $0.01 \mathrm{M} \quad \mathrm{KH}_{2} \mathrm{PO}_{4}$ $(\mathrm{pH}=4.3)$ :methanol $=75: 25$ mixture $(1: 4 w / v)$ with a tissue blender. Tissue homogenates were stored at $-70^{\circ} \mathrm{C}$ until HPLC analysis.

\subsection{Plasma corticosterone analysis}

The plasma concentration of corticosterone was measured by enzyme-linked immunosorbent assay (ELISA). A Mouse/Rat Corticosterone ELISA (BioVendor, Bio-Kasztel Ltd., Hungary) kit was used for the quantification of corticosterone, according to the manufacturers' manual.

\subsection{HPLC analysis}

\subsubsection{Chemicals and reagents}

HPLC-grade acetonitrile, methanol, isopropyl alcohol and ammonium hydroxide were purchased from VWR International Ltd. (Debrecen, Hungary). Potassium dihydrogen phosphate and glycine were of analytical grade and purchased from Sigma-Aldrich (Budapest, Hungary). The water was purified and deionized by Milli-Q system (Millipore, Milford, MA, USA). Haloperidol $\left(5 \mathrm{mg} \mathrm{m}^{-1}\right.$ haloperidol, Gedeon Richter Plc., Hungary) and Seduxen $\left(5 \mathrm{mg} \mathrm{ml}^{-1}\right.$ diazepam, Gedeon Richter Plc., Hungary) injections were applied to treat the animals and as standards.

\subsubsection{HPLC system and conditions}

The HPLC apparatus consisted of a Shimadzu system (Shimadzu Corporation, Kyoto, Japan) equipped with a solvent delivery system (LC-20 CE), DGU-20A 3 on-line degasser, SIL 20A HT auto injector, CTO20A column oven, SPD-M20A photodiode-array detector and CBM-20A system controller. The system control and data acquisition were performed by Shimadzu "LC solution" software (Shimadzu Corporation, Kyoto, Japan).

The chromatographic separations were performed on a Kromasil Eternity C18 $(5 \mu \mathrm{m}, 150 \mathrm{~mm} \times 4.6 \mathrm{~mm})$ analytical column, protected by a $5 \mu \mathrm{m}$ guard column. The column temperature was kept constant at $35^{\circ} \mathrm{C}$. Separations were performed in isocratic mode. The mobile phase used for the separation consisted of acetonitrile:water:isopropyl alcohol:ammonium hydroxide $=40: 50: 10: 0,025(v / v / v / v)$ pumped at a flow rate of $1 \mathrm{ml} \mathrm{min}^{-1}$. The mobile phase was filtered by a Millipore 
A.

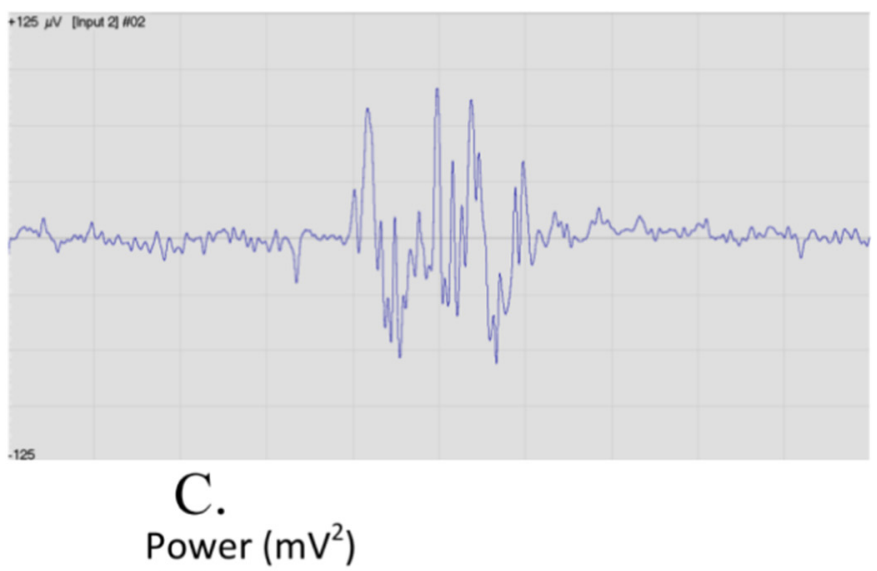

B.

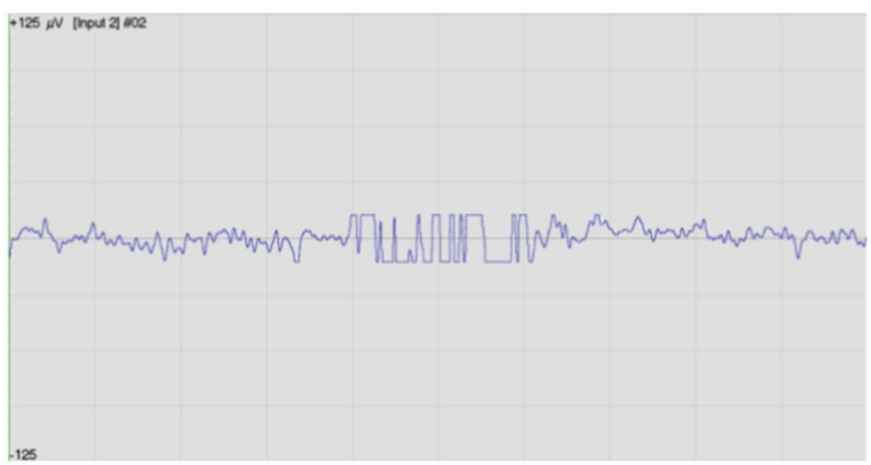

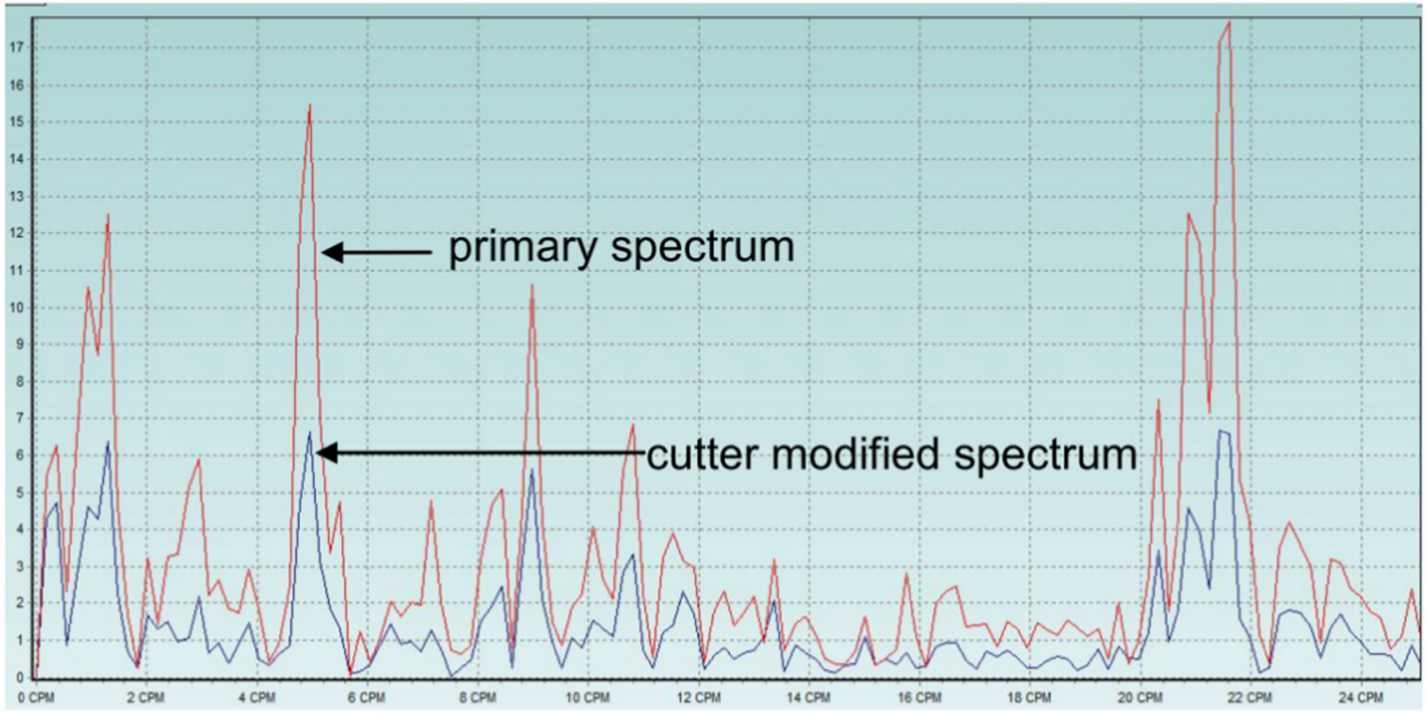

Frequency (cpm)

Fig. 1. The primary myoelectric signal of the gastrointestinal tract in rat with outlier peaks of motion artifact (A) was cut by the software in-built digital cutter to remove the motion artifacts (B). The specific spectra were gained by fast Fourier transformation (FFT). The red curve represents the FFT spectrum of the primary spectrum with motion artifacts, while the blue curve shows the spectrum after the digital cut. The cycle per minute (cpm) frequencies of the peak values remained the same after modification, but with lower power spectrum density maximum values (C). (For interpretation of the references to colour in this figure legend, the reader is referred to the web version of this article.)

vacuum filtration system equipped with a $0.45 \mu \mathrm{m}$ pore size filter and degassed by ultra-sonication. The detection wavelength was $245 \mathrm{~nm}$.

\subsubsection{Preparation of standard solutions, calibration samples}

Haloperidol injection and diazepam injection were diluted with normal saline to the concentration of $0.25 \mathrm{mg} \mathrm{ml}^{-1}$, and then further diluted with mobile phase to obtain a series of working standard solutions. Stock solutions were stored at $-20{ }^{\circ} \mathrm{C}$ and working solutions were kept refrigerated at $2-6^{\circ} \mathrm{C}$. The working solutions were used to prepare 6 calibration samples in blank serum $(0.01,0.05,0.1,0.5,1$ and $1.5 \mu \mathrm{g} \mathrm{ml}^{-1}$ ) for haloperidol and diazepam. The calibration samples of haloperidol for brain, lung and liver tissues were prepared at the following concentrations: $0.05,0.1,0.5,1,2.5$ and $5 \mu \mathrm{g} \mathrm{g}^{-1}$.

\subsubsection{Sample preparation}

An aliquot of plasma or tissue homogenate sample $(200 \mu \mathrm{l})$ was combined with $20 \mu \mathrm{l}$ of $50 \mu \mathrm{g} \mathrm{ml}^{-1}$ internal standard solution and $100 \mu \mathrm{l} 1 \mathrm{M}$ glycine buffer $(\mathrm{pH}=10.5)$, then $1.5 \mathrm{ml}$ acetonitrile was added. The mixture was vortexed for $1.5 \mathrm{~min}$ and centrifuged at $12,000 \mathrm{rpm}$ for $10 \mathrm{~min}$ at $4^{\circ} \mathrm{C}$. The supernatant was transferred to another clean glass tube and evaporated to dryness under a stream of nitrogen at $40{ }^{\circ} \mathrm{C}$. The residue was reconstituted in $100 \mu \mathrm{l}$ mobile phase and vortex-mixed for $10 \mathrm{~s}$; a volume of $20 \mu \mathrm{l}$ solution was injected for analysis.

\subsubsection{Calibration curve}

Six-point calibration curves, prepared in triplicate, showed good linearity $\left(R^{2}=0.9450 \pm 0.010\right.$ and $\left.R^{2}=0.9980 \pm 0.008\right)$ for diazepam and haloperidol, respectively. The recovery of diazepam from plasma samples was $78.35 \pm 3.68 \%$. The recovery of haloperidol from plasma and organ samples was $96.4 \pm 4.33 \%$ and $98.7 \pm 3.02 \%$, respectively. The limits of quantification were 10 and $5 \mathrm{ng} \mathrm{ml}^{-1}$ for diazepam and haloperidol, respectively. The limits of detection were 3 and $1 \mathrm{ng} \mathrm{ml}^{-1}$ for diazepam and haloperidol, respectively.

\subsection{Contractility studies in isolated organ bath}

Before measurement, rats were fasting for $24 \mathrm{~h}$. The animals were terminated by $\mathrm{CO}_{2}$ inhalation. The stomach, ileum and cecum were dissected, rinsed with Tyrode solution (composition in mM: $137 \mathrm{NaCl}, 3$ $\mathrm{KCl}, 1 \mathrm{CaCl}_{2}, 1 \mathrm{MgCl}_{2}, 12 \mathrm{NaHCO}_{3}, 0.4 \mathrm{NaH}_{2} \mathrm{PO}_{4}, 6$ glucose, $\mathrm{pH} 7.4$ ) and cleaned from fat. Strips from the stomach were prepared as 
A.

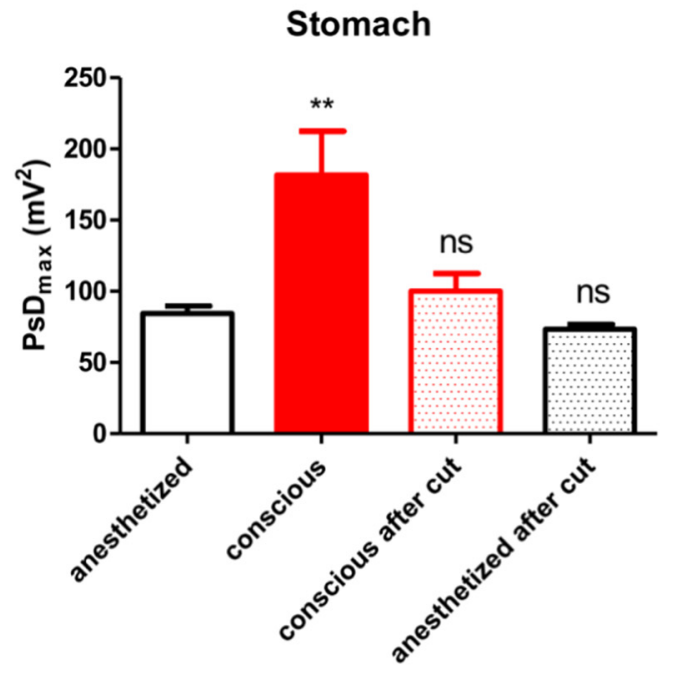

B.

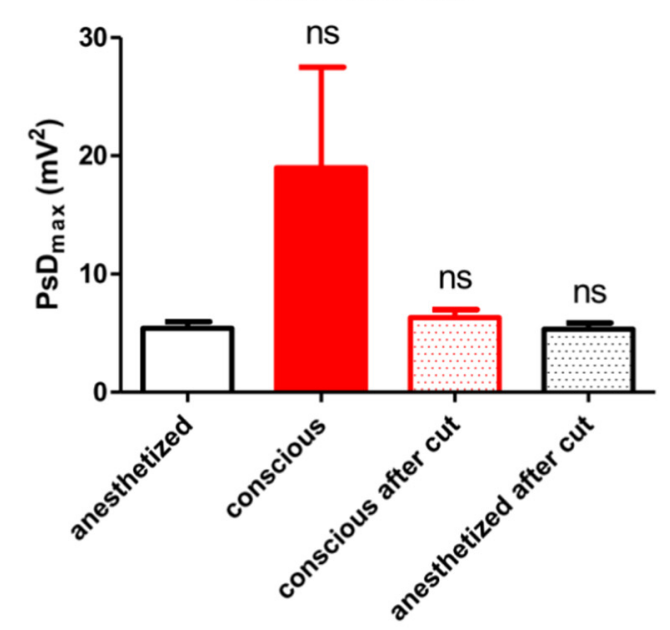

C.

Large intestine

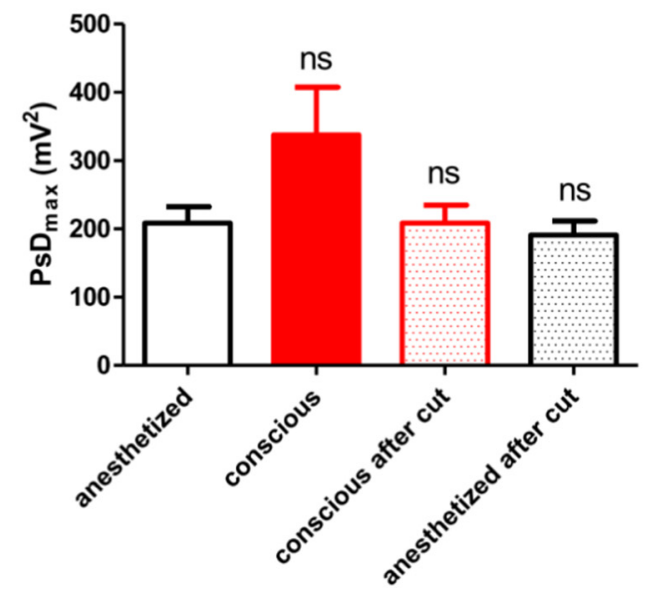

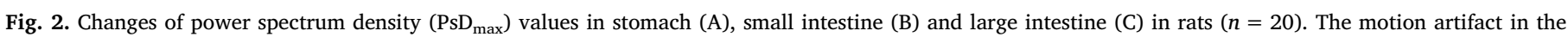

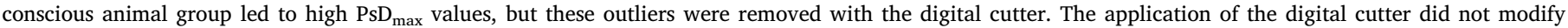

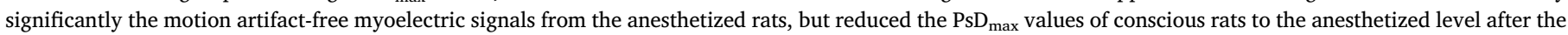
cut. (ns: not significant; $p<0.01^{* *}$ ).

described earlier [13]. The ileum and the cecum were cut into 5-mmlong muscle rings. The smooth muscle samples were mounted vertically in an organ bath containing $10 \mathrm{ml}, 37^{\circ} \mathrm{C}$ Tyrode buffer and carbogen $\left(95 \% \mathrm{O}_{2}+5 \% \mathrm{CO}_{2}\right)$ was bubbled through it. The initial tension of the tissues was set to $1.5 \mathrm{~g}$. The samples were incubated for $60 \mathrm{~min}$, the buffer solution was changed in every $15 \mathrm{~min}$. After the incubation period, the control contractions of smooth muscle were evoked by $\mathrm{KCl}$ $(25 \mathrm{mM})$ and a cumulative dose-response curve of $10^{-4}-10^{-9} \mathrm{M}$ diazepam or haloperidol was obtained. The activity of gastric strips, ileal and cecal rings was measured with a gauge transducer (SG-02, MDE $\mathrm{GmbH}$, Walldorf, Germany) and recorded with a SPEL Advanced ISOSYS Data Acquisition System (MDE GmbH, Walldorf, Germany). The haloperidol or diazepam effects were characterized by the percentage of the area under curves (AUC) values of recorded contractions before and after adding them into the organ bath. The analyzed periods were $5 \mathrm{~min}$ both for the control and the drug-altered contractions.

\section{Results}

The myoelectric activity of the GI tract was detected in awake rats. The motion artifacts had approximately 4-fold higher signals on the primary record as compared with the GI tract activity. The motion artifact was separated from the basal electric activity of the GI smooth muscle by the cutter built into the software. With this modification, the motion artifact-induced peaks were cut in the primary curves (Fig. 1A, B). When the modified EMG curves were transformed by FFT, the $\mathrm{PsD}_{\max }$ values on the modified spectra were reduced, but the cpm frequencies of the PsDmax values remained in the same range (Fig. 1C).

The digital cut reduced the motion artifact elevated $\mathrm{PsD}_{\max }$ values to the range of values in anesthetized rats, but did not further reduce the values detected in anesthetized rats (Fig. 2).

Immobilization stress significantly increased the plasma level of corticosterone. The rate of increase was approximately 3-fold as compared with the resting value (resting value: $75.4 \mathrm{ng} \mathrm{ml}^{-1}$, stress value: $214.5 \mathrm{ng} \mathrm{ml}^{-1}$ ) (Fig. 3A). In parallel, the $\mathrm{PsD}_{\max }$ values in the whole GI tract were elevated 1.5-2-fold during immobilization. The greatest increase was found in the gastric values, although the increase in the gastric $\mathrm{PsD}_{\max }$ values was not significantly higher than the increase in the small or large intestine values (Fig. 3B).

Diazepam treatment reduced the resting EMG activity by $40-60 \%$, while the stress-induced PsDmax values were set back to the resting level, reaching around $100 \%$ in all the three GI tract sections. In the large intestine, immobilization stress did not induce a significant increase in the presence of diazepam (Fig. 4A). Haloperidol treatment reduced the resting EMG activity by $40 \%$, but immobilization stress was not able to induce significant elevation in the myoelectric activity of the 
A.

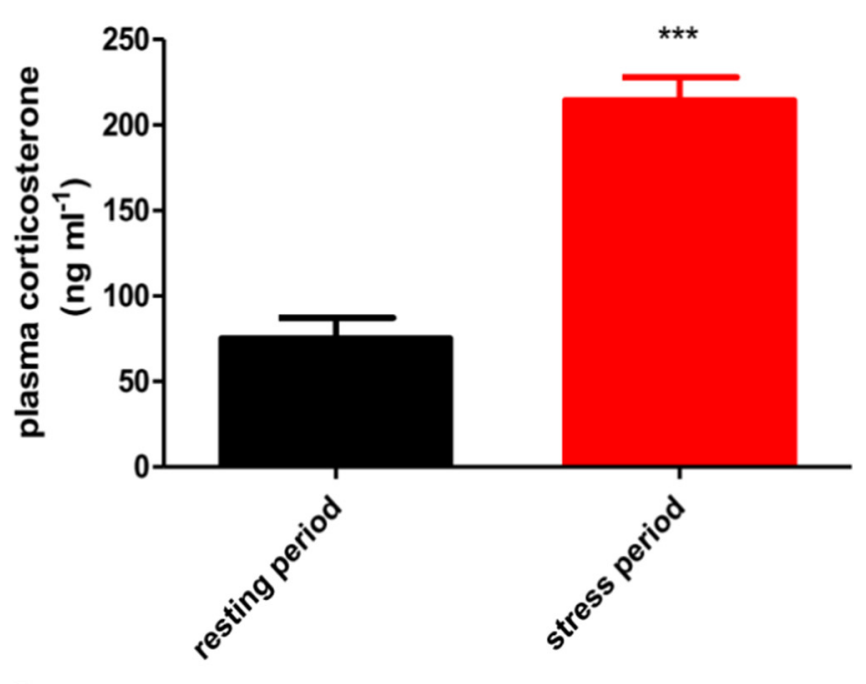

B.

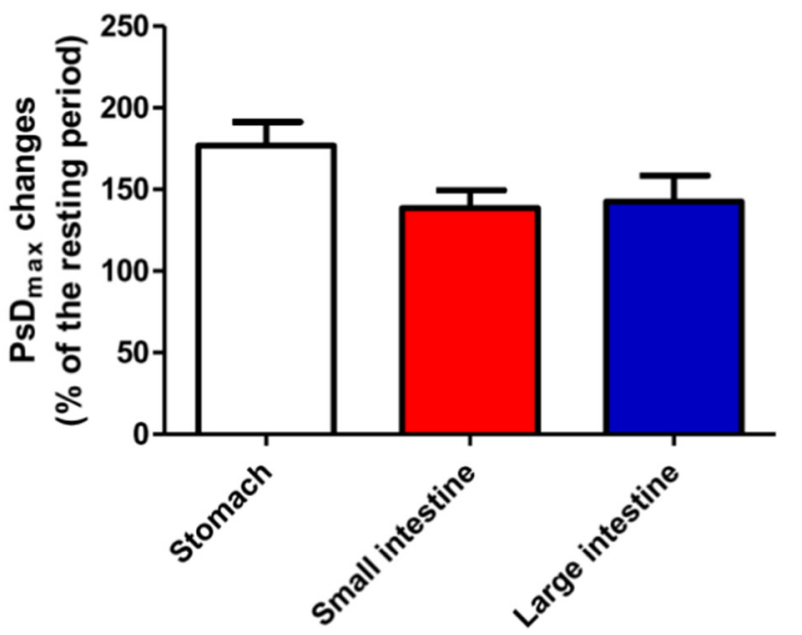

Fig. 3. Immobilization stress induced a significant increase in the plasma corticosterone level of rat $(n=20)$ as compared with the resting period $(* * *$ : $p<0.001$ ) (A). The stress condition also raised the power spectrum density $\left(\mathrm{PsD}_{\max }\right)$ values of the FFT spectra from the stomach, small intestine and large intestine as compared with the resting period. (B).

whole GI tract (Fig. 4B).

Both diazepam and haloperidol treatments reduced the plasma corticosterone levels during the resting period by approximately $30 \%$, however, these alterations were not significant. Only haloperidol was able to blot out the stress hormone inducing effect of immobilization (Fig. 5).

The plasma level of diazepam was $0.42 \mu \mathrm{g} \mathrm{ml}^{-1}$ at the end of the resting period (30 min after drug administration), and its level was reduced to $0.13 \mu \mathrm{g} \mathrm{ml}^{-1}$ at the end of the stress period $(60 \mathrm{~min}$ after drug administration). Haloperidol was not detectable in the plasma even at the end of the resting period, but it was found in the brain, liver and lung in a concentration of $0.30,1.91$ and $2.23 \mu \mathrm{g} \mathrm{g}^{-1}$, respectively. At the end of the stress period, the levels of haloperidol were still considerable in these organs (brain: $0.16 \mu \mathrm{g} \mathrm{g}^{-1}$, liver: $1.33 \mu \mathrm{g} \mathrm{g}^{-1}$, lung: $0.96 \mu \mathrm{g} \mathrm{g}^{-1}$ ). After statistical analysis, only the pulmonary level of haloperidol at the end of the stress period was significantly lower as compared with the end of the resting period (Fig. 6).
A.

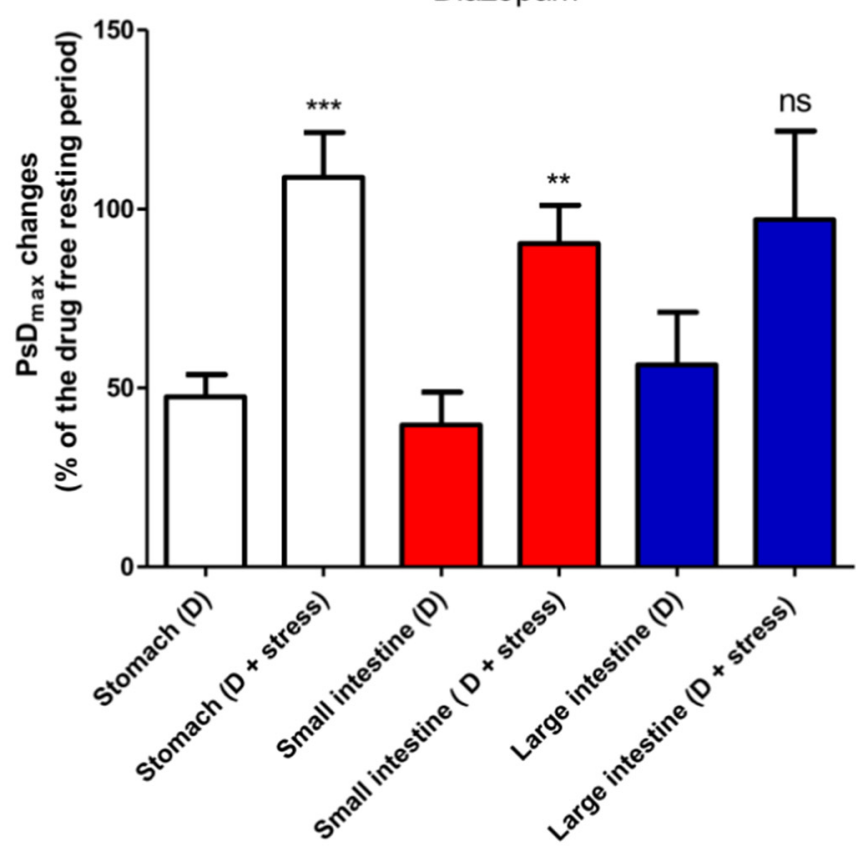

B.

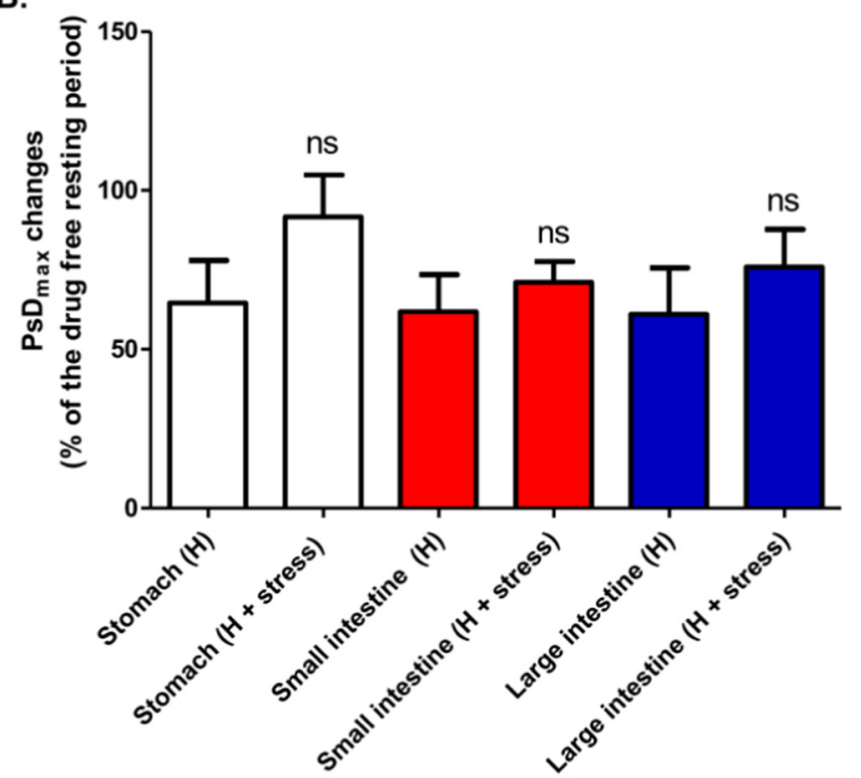

Fig. 4. Changes in power spectrum density maximum $\left(\mathrm{PsD}_{\max }\right)$ values after diazepam (A) or haloperidol (B) treatments in conscious rats $(n=15$ for each group) under immobilization-induced stress. The values are expressed as the percentage of the resting values without drug treatment. Both diazepam and haloperidol reduced the myoelectric activities of the gastrointestinal smooth muscles. They reduced the $\mathrm{PsD}_{\max }$ values during the stress-free period, however, only haloperidol was able to inhibit the increase in the $\mathrm{PsD}_{\max }$ value during immobilization stress. (ns: not significant; $p<0.01^{* *} ; p<0.001^{* * *}$ ).

Significant correlation was found between the drug induced change in the $\mathrm{PsD}_{\max }$ values of the stomach, small intestine or large intestine and the change in corticosterone plasma levels. The levels of correlations were the same in all the three GI tract segments (Fig. 7).

Neither diazepam nor haloperidol elicited any significant relaxing effect on gastric strip, ileal or cecal rings in isolated organ studies (Fig. 8). 


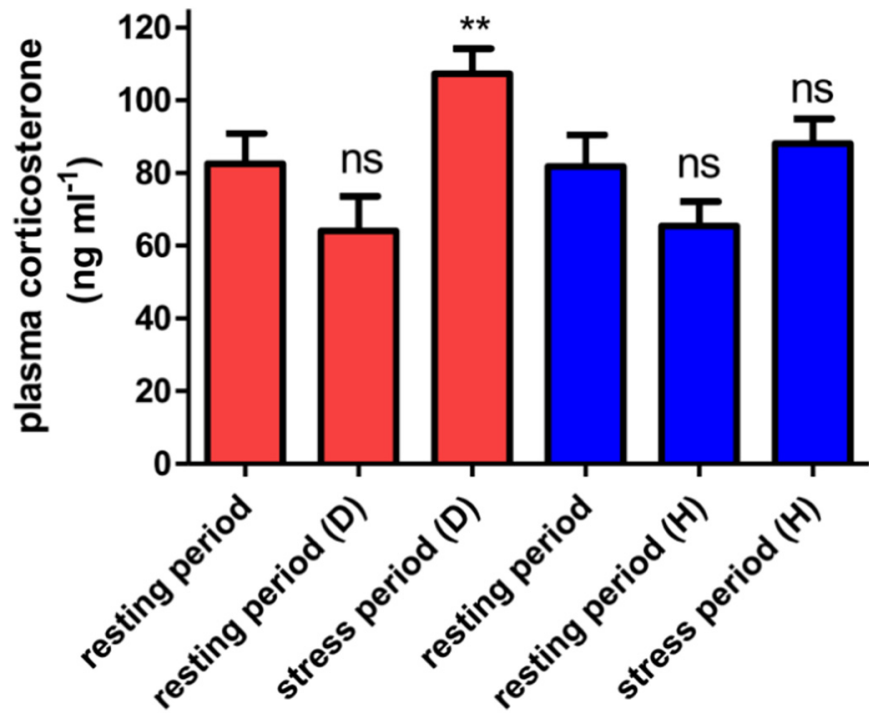

Fig. 5. Alterations of plasma corticosterone levels by drug treatments (red columns: diazepam, blue columns: haloperidol) and immobilization stress in rats ( $n=15$ for each group). The hormone level was elevated significantly by stress compared to the control level. Diazepam $\left(5 \mathrm{mg} \mathrm{kg}^{-1}\right)$ or haloperidol $\left(1 \mathrm{mg} \mathrm{kg}^{-1}\right)$ treatment alone reduced the plasma corticosterone values, although the alterations were not significant. Only haloperidol was able to inhibit the increase in the plasma corticosterone level during immobilization stress. (D. diazepam; H: haloperidol; ns: not significant; ${ }^{*} p<0.05 ;{ }^{* *} ; p<0.01$ ). (For interpretation of the references to colour in this figure legend, the reader is referred to the web version of this article.)

\section{Discussion}

The non-invasive and reliable measurement of stress condition by physiological parameters is still an unsolved clinical problem. Although the relationships between stress condition and organ systems like cardiovascular, dermal or GI systems are obvious, the level of stress is mostly appraised by psychological tests [14]. A new technique and instrument measuring both psychological and physiological parameters have been reported for stress evaluation. Among the physiological parameters, this instrument detects cardiovascular and dermal responses [15], however, the GI parameters are not involved in the analysis. Although the in vivo GI motility can be assessed by the measurement of gastric content [16] or by the detection of a colored marker in the intestine [17], these methods evaluate the GI responses after the termination of the experimental animals.

The consequences of the function of the brain-gut axis include the stress induced alterations in the GI tract motility, which may lead to inflammatory bowel disease, peptic ulcer and many other GI tract disorders [18]. Acute stress response enhances the motility in the GI tract, which is controlled by peripheral neuropeptides and corticosteronereleasing hormone [19]. Previously we developed an in vivo smooth muscle EMG method to measure the GI tract (stomach, small and large intestine) myoelectric activity, which showed very strong correlation with the mechanical contractions in anesthetized rats [11]. We hypothesized that this method can be applicable to awake rats and to measuring the correlation between GI tract motility and stress condition.

Awake EMG measurements are always disturbed by motion artifacts, especially in experimental animals where the movements cannot be reduced by self-control. Therefore, our first task was to identify the EMG signals of motion artifacts and then develop a digital cutter to remove them from the record without significant loss of smooth muscle data. The motion artifacts had much bigger EMG signals than the smooth muscle did, thus their identification and removal was an easy task by the newly developed digital cutter. The goodness of cut was proved by the FFT spectrum analysis, in which the characteristic peaks remained at the same frequency, only their $\mathrm{PsD}_{\max }$ values were reduced, which could be anticipated before cut. After cut, the smooth muscle EMG record showed basal activity like in anesthetized animals, where the motion artifact is a nonsignificant factor. These results suggest that we have successfully kept the smooth muscle signals with the effective removal of motion artifact.

Acute immobilization, which increases the plasma corticosterone level, is an accepted stress method in rats [20]. Immobilization can increase the stress factors within quite a short period of time, 30-60 min can be enough for the significant elevation of stress hormone

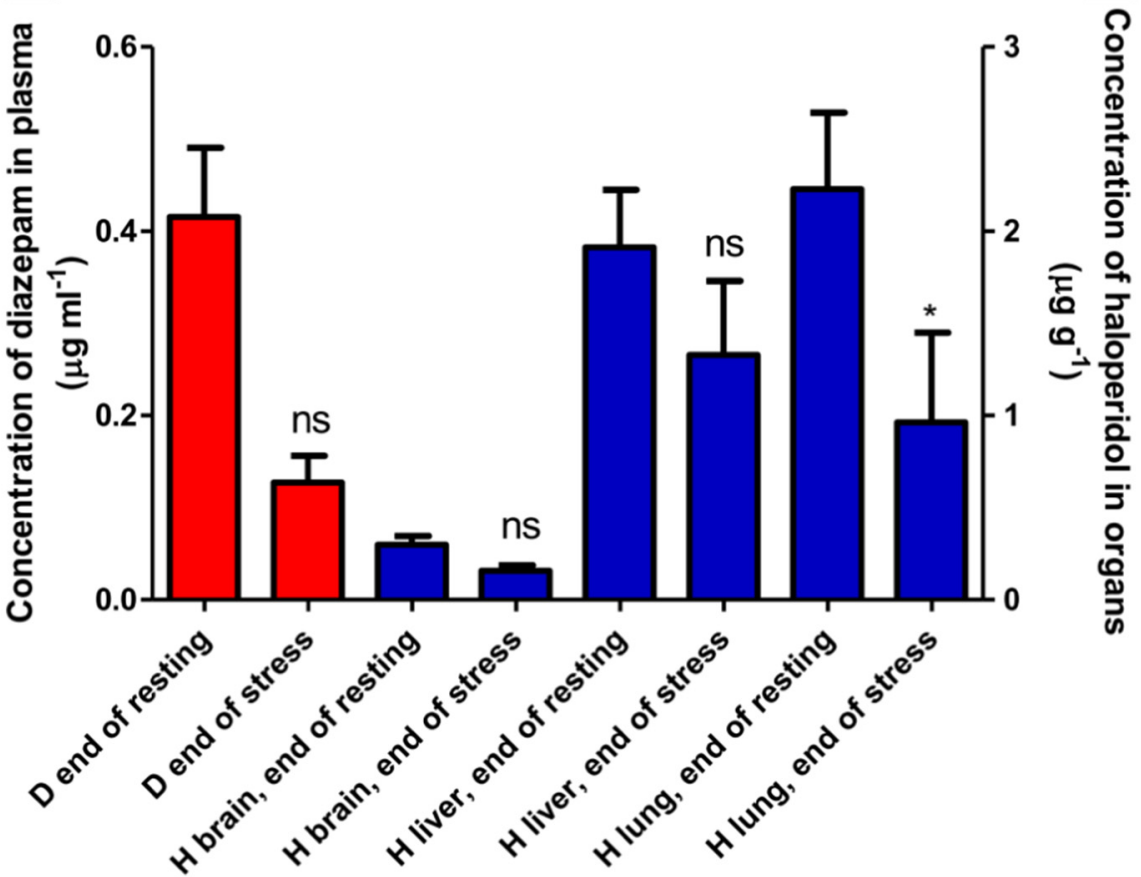

Fig. 6. Plasma levels of diazepam (red columns) and organ levels of haloperidol (blue columns) after $30 \mathrm{~min}$ (end of resting period) and $60 \mathrm{~min}$ (end of stress period) of intraperitoneal administration $\left(5 \mathrm{mg} \mathrm{kg}^{-1}\right.$ for diazepam, $1 \mathrm{mg} \mathrm{kg}^{-1}$ for haloperidol) in rats ( $n=15$ for each group). The drug levels were determined by the HPLC method. (D: diazepam; H: haloperidol; ns: not significant; $*: p<0.05$ ). (For interpretation of the references to colour in this figure legend, the reader is referred to the web version of this article.) 
A.

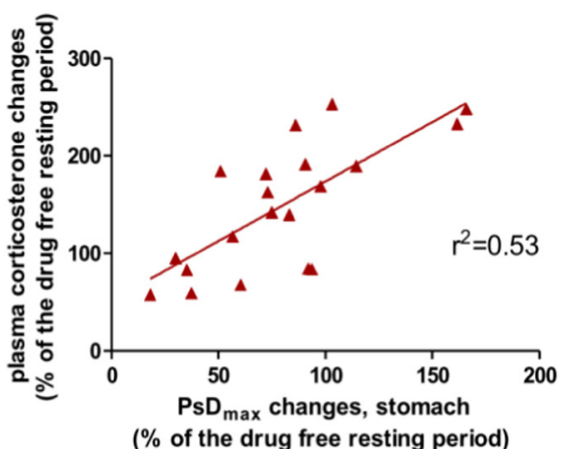

B.

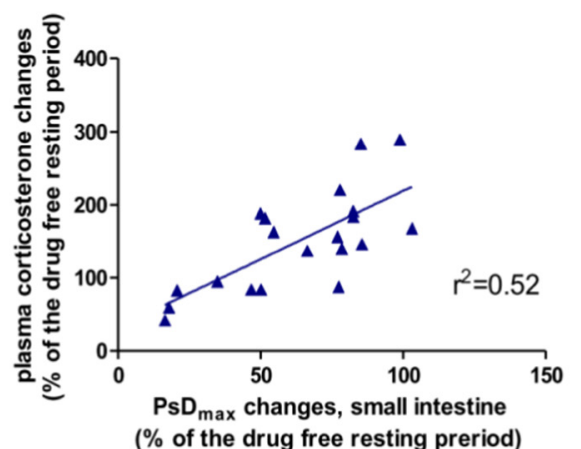

C.

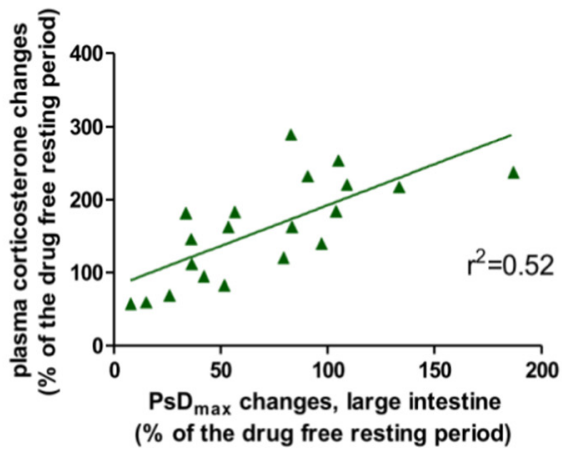

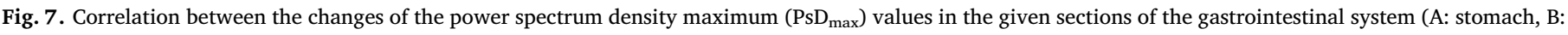

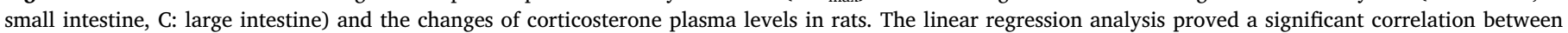
$\mathrm{PsD}_{\text {max }}$ and corticosterone alteration.

A.

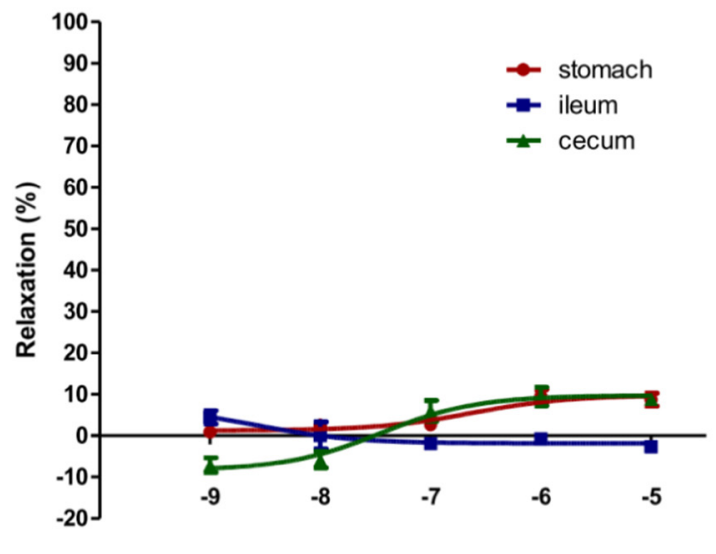

log. diazepam (M)
B.

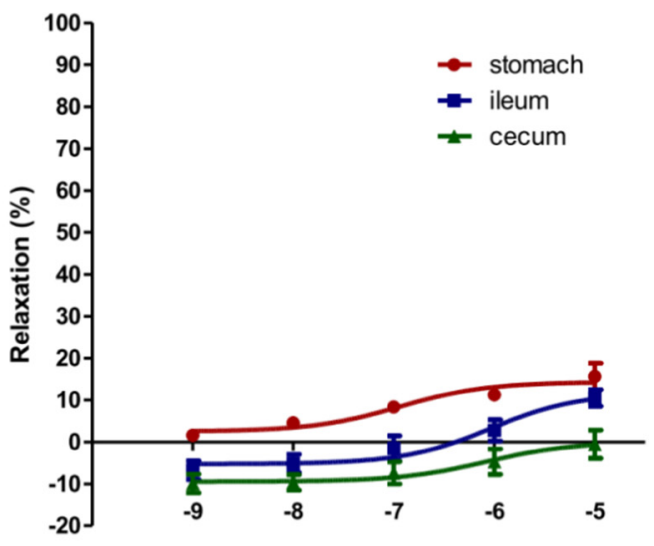

log. haloperidol (M)

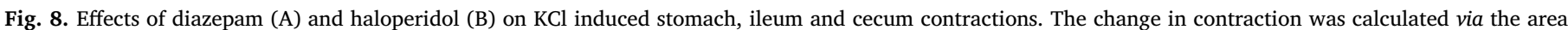
under the curve and expressed in $\% \pm$ SEM. No significant effects were observed directly on the investigated GI samples induced by the drugs.

levels in rodents [21,22]. Considering this fact, we applied immobilization to our rats for $30 \mathrm{~min}$, which period is also suitable for the detection of GI tract myoelectric activity. Both corticosterone and $\mathrm{PsD}_{\max }$ values were increased during the immobilization, and the correlation found between the two parameters indicates that the severity of acute stress can be predicted by the detection of smooth muscle EMG in awake rats. This correlation was reinforced by the results gained after treatment with central nervous system depressants.

Diazepam is a well-known anxiolytic agent, which elicits a moderate stress reducing effect in rats [23]. Haloperidol is a strong antipsychotic, which can cease the whole stress response, although it can induce oxidative stress in the brain but only in the case of chronic treatment [24]. However, in our experiments the animals were terminated after 60 min of single drug treatment, therefore the oxidative stress-inducing effect of haloperidol could not develop. The plasma levels of both diazepam and haloperidol were checked $30 \mathrm{~min}$ (end of resting period) and $60 \mathrm{~min}$ (end of stress period) after their administration. The measurement of plasma levels was important to justify the presence of effective concentrations during our experiments. In the case of diazepam, the lowest plasma level was around $0.1 \mu \mathrm{g} \mathrm{ml}^{-1}$ at the end of the experiments, which provides sufficient anxiolytic action in rats [25]. Haloperidol has special pharmacokinetics with a fast distribution into different organs, thus the concentration of haloperidol in these organs can be much higher than its plasma concentration after $1 \mathrm{~h}$ of parenteral administration [26]. In our experiments, the haloperidol plasma level was under the limit of our detection even after $30 \mathrm{~min}$, but significant amounts of drug were found in the brain, liver and lung. Since around $0.1 \mu \mathrm{g} \mathrm{g}^{-1}$ concentration of haloperidol is considered to have therapeutic action in rats [27], the $0.16 \mu \mathrm{g} \mathrm{g}^{-1}$ concentration that was found after $1 \mathrm{~h}$ in the brain of our rats seems to be satisfactory to provide the required neuroleptic effect.

While haloperidol blocked the rise of corticosterone during acute stress, diazepam was only able to reduce the increase in the stress hormone level. This difference between the effects of these two types of drug was clearly detectable in the smooth muscle EMG response of the GI tract, especially in the gastric and the small intestine $\mathrm{PsD}_{\max }$ values. The isolated organ bath studies proved that neither diazepam nor haloperidol had a direct smooth muscle relaxing effect on the GI tract smooth muscles, therefore the responses found in awake rats originated from their central nervous system effects, possibly mediated through the brain-gut axis.

\section{Conclusion}

Based on these results, it can be concluded that our smooth muscle EMG instrument after FFT analysis can measure the level of acute stress in awake rats, which shows correlation with the stress hormone plasma level. This finding is further evidence for the function of the brain-gut axis. Our technique is also applicable to the investigation of different drugs affecting the central nervous system through the GI tract myoelectric response. We suppose that this method serves as a good basis for the development of a new clinical tool to assess the stress and 
anxiety levels of patients in different kinds of psychological disorders and during pharmacotherapy. Our method is the first one that can measure the stress response via the GI tract reactions. This kind of monitoring of GI tract myoelectric responses may open a new perspective in the diagnosis and therapy of psychosomatic disorders.

\section{Conflict of interest statement}

The authors declare that there are no conflicts of interest.

\section{Acknowledgement}

This work was supported by project PIAC_13-1-2013-0201, National Research, Development and Innovation Office, Hungarian Government. This research was supported by the EU-funded Hungarian grant EFOP-3.6.1-16-2016-00008.

The technical support of Zoltánné Csiszár is highly appreciated.

\section{References}

[1] J.F. Cryan, S.M. O'Mahony, The microbiome-gut-brain axis: from bowel to behavior, Neurogastroenterol. Motil. 23 (3) (2011) 187-192.

[2] X. Chen, R. D'Souza, S.T. Hong, The role of gut microbiota in the gut-brain axis: current challenges and perspectives, Protein Cell 4 (6) (2013) 403-414.

[3] G. De Palma, S.M. Collins, P. Bercik, The microbiota-gut-brain axis in functional gastrointestinal disorders, Gut Microbes 5 (3) (2014) 419-429.

[4] D.A. Drossman, Functional gastrointestinal disorders: history, pathophysiology, clinical features and Rome IV, Gastroenterology 150 (6) (2016) 1262-1279.

[5] L. Van Oudenhove, Q. Aziz, The role of psychosocial factors and psychiatric disorders in functional dyspepsia, Nat. Rev. Gastroenterol. Hepatol. 10 (3) (2013) $158-167$.

[6] E.G. Severance, E. Prandovszky, J. Castiglione, R.H. Yolken, Gastroenterology issues in schizophrenia: why the gut matters, Curr. Psychiatry Rep. 17 (5) (2015) 27.

[7] K.M. Sanders, S.M. Ward, G.W. Hennig, Problems with extracellular recording of electrical activity in gastrointestinal muscle, Nat. Rev. Gastroenterol. Hepatol. 13 (12) (2016) 731-741.

[8] F. Gabsteiger, H. Leutheuser, P. Reis, M. Lochmann, B.M. Eskofier, ICA-based reduction of electromyogenic artifacts in EEG data: comparison with and without EMG data, Conference Proceedings: Annual International Conference of the IEEE Engineering in Medicine and Biology Society IEEE Engineering in Medicine and Biology Society Annual Conference, 2014 2014, pp. 3861-3864.

[9] C.J. De Luca, L.D. Gilmore, M. Kuznetsov, S.H. Roy, Filtering the surface EMG signal: movement artifact and baseline noise contamination, J. Biomech. 43 (8) (2010) 1573-1579.

[10] A. Fratini, M. Cesarelli, P. Bifulco, M. Romano, Relevance of motion artifact in electromyography recordings during vibration treatment, J. Electromyogr. Kinesiol. 19 (4) (2009) 710-718.

[11] K.F. Szucs, A. Nagy, G. Grosz, Z. Tiszai, R. Gaspar, Correlation between slow-wave myoelectric signals and mechanical contractions in the gastrointestinal tract: advanced electromyographic method in rats, J. Pharmacol. Toxicol. Methods 82 (2016) 37-44.

[12] K.F. Szucs, G. Grosz, M. Sule, A. Nagy, Z. Tiszai, R. Samavati, et al., Identification of myoelectric signals of pregnant rat uterus: new method to detect myometrial contraction, Croat. Med. J. 58 (2) (2017) 141-148.

[13] J.R. Vane, A sensitive method for the assay of 5-hydroxytryptamine, Br. J. Pharmacol. Chemother. 12 (3) (1957) 344-349.

[14] A. Hinz, A.M. Klein, E. Brahler, H. Glaesmer, T. Luck, S.G. Riedel-Heller, et al., Psychometric evaluation of the generalized anxiety disorder screener GAD-7, based on a large German general population sample, J. Affect. Disord. 210 (2017) $338-344$.

[15] E. Neureiter, L. Hajfani, A. Ahnis, A. Mierke, M. Rose, G. Danzer, et al., An introduction to the 'Psycho-Physiological-Stress-Test' (PPST)-a standardized instrument for evaluating stress reactions, PLoS One 12 (12) (2017) e0187859.

[16] M. Bulbul, O. Sinen, B. Gemici, V.N. Izqut-Uysal, Opposite effects of central oxytocin and arginine vasopressin on changes in gastric motor function induced by chronic stress, Peptides 87 (2017) 1-11.

[17] C.M. Keenan, M.A. Storr, G.A. Thakur, J.T. Wood, J. Wager-Miller, A. Straiker, et al., AM841, a covalent cannabinoid ligand, powerfully slows gastrointestinal motility in normal and stressed mice in a peripherally restricted manner, Br. J. Pharmacol. 172 (9) (2015) 2406-2418.

[18] P.C. Konturek, T. Brzozowski, Konturek S.J. Stress, The gut: pathophysiology, clinical consequences, diagnostic approach and treatment options, J. Physiol. Pharmacol. 62 (6) (2011) 591-599.

[19] S.C. Forbes, H.M. Cox, Peptide YY, neuropeptide Y and corticotrophin-releasing factor modulate gastrointestinal motility and food intake during acute stress, Neurogastroenterol. Motil. 26 (11) (2014) 1605-1614.

[20] L.A. Mendez-Cuesta, B. Marquez-Valadez, V. Perez-De la Cruz, P.D. Maldonado, R.A. Santana, C. Escobar-Briones, et al., Early changes in oxidative stress markers in a rat model of acute stress: effect of 1-carnitine on the striatum, Basic Clin. Pharmacol. Toxicol. 109 (2) (2011) 123-129.

[21] A. Uwaya, H. Lee, J. Park, H. Lee, J. Muto, S. Nakajima, et al., Acute immobilization stress following contextual fear conditioning reduces fear memory: timing is essential, Behav. Brain Funct. 12 (1) (2016) 8.

[22] N.T. Bello, A.L. Walters, J.L. Verpeut, J. Caverly, Dietary-induced binge eating increases prefrontal cortex neural activation to restraint stress and increases binge food consumption following chronic guanfacine, Pharmacol. Biochem. Behav. 125 (2014) 21-28.

[23] L.A. Mendez-Cuesta, B. Marquez-Valadez, V. Perez-De La Cruz, C. Escobar-Briones, S. Galvan-Arzate, Y. Alvarez-Ruiz, et al., Diazepam blocks striatal lipid peroxidation and improves stereotyped activity in a rat model of acute stress, Basic Clin. Pharmacol. Toxicol. 109 (5) (2011) 350-356.

[24] O.M. Abdel-Salam, E.R. Youness, Y.A. Khadrawy, A.A. Sleem, Brain and liver oxidative stress after sertraline and haloperidol treatment in mice, J. Basic Clin. Physiol. Pharmacol. 24 (2) (2013) 115-123.

[25] W.R. Martin, J.W. Sloan, E.P. Wala, Precipitated abstinence in the diazepam-dependent rat, Pharmacol. Biochem. Behav. 46 (3) (1993) 683-688.

[26] H. Miyazaki, Y. Matsunaga, K. Nambu, Y. Oh-e, K. Yoshida, M. Hashimoto, Disposition and metabolism of $\left[{ }^{14} \mathrm{C}\right]$-haloperidol in rats, Arzneimittelforschung 36 (3) (1986) 443-452.

[27] M. Ikemura, Y. Nakagawa, K. Shinone, H. Inoue, M. Nata, The blood concentration and organ distribution of haloperidol at therapeutic and toxic doses in severe fatty liver disease, Legal Med. 14 (3) (2012) 147-153. 